\title{
La politique de développement de la communauté de travail Swissaid / Action de Carême / Pain pour le prochain / Helvetas
}

Die Entwicklungspolitik der Arbeitsgemeinschaft Swissaid / Fastenopfer / Brot für brüder / Helvetas

\section{Richard Gerster}

\section{OpenEdition Journals}

Édition électronique

URL : http://journals.openedition.org/aspd/1140

DOI : $10.4000 /$ aspd. 1140

ISSN : 1663-9669

\section{Éditeur}

Institut de hautes études internationales et du développement

\section{Édition imprimée}

Date de publication : 31 août 1982

Pagination : 161-167

ISSN : 1660-5934

\section{Référence électronique}

Richard Gerster, «La politique de développement de la communauté de travail Swissaid / Action de Carême / Pain pour le prochain / Helvetas ", Annuaire suisse de politique de développement [En ligne], 2 | 1982, mis en ligne le 27 janvier 2013, consulté le 08 septembre 2020. URL : http:// journals.openedition.org/aspd/1140; DOI : https://doi.org/10.4000/aspd.1140

Ce document a été généré automatiquement le 8 septembre 2020

(c) The Graduate Institute I Geneva 


\section{La politique de développement de la communauté de travail Swissaid / Action de Carême / Pain pour le prochain / Helvetas}

Die Entwicklungspolitik der Arbeitsgemeinschaft Swissaid / Fastenopfer / Brot für brüder / Helvetas

Richard Gerster

\section{NOTE DE L'ÉDITEUR}

En français, résumé seulement. Lire l'article original en allemand dans Schweizerisches Jahrbuch für Entwicklungspolitik : « Die Entwicklungspolitik der Arbeitsgemeinschaft Swissaid / Fastenopfer / Brot für brüder / Helvetas», http://sjep.revues.org/953.

\section{RÉSUMÉS}

Les flux financiers mineurs provenant des organisations non-gouvernementales de développement, par rapport aux investissements privés et à l'APD, ne doivent pas tromper sur l'importance et la qualité des activités de telles organisations, qui se déploient dans quatre domaines : la réalisation de projets de développement, tendant principalement vers la "SelfReliance "; le travail d'information auprès de la jeunesse et des écoles; l'information et la conscientisation $\mathrm{du}$ public et la participation à l'élaboration de la politique suisse du 
développement.

Les ONG suisses se veulent le porte-parole des couches défavorisées des PVD auprès des organes de la politique extérieure commerciale suisse et de la politique de coopération au développement. Les ONG suisses rassemblent ainsi nombre de ceux qui, mécontents des relations entre la Suisse et le Tiers Monde, cherchent une possibilité de s'exprimer publiquement.

La communauté de travail, fondée en 1969, a débouché sur la constitution de trois organismes communs : le Service Information Tiers Monde (I3M), le Service Ecole Tiers Monde (E3M), et le poste de coordinateur de la politique de développement.

- I3M, fondé en 1971, est représenté à Berne et à Lausanne ; ses buts sont l'information de la presse et du public au moyen de bulletins et de dossiers, et l'offre d'une documentation sur les problèmes généraux du développement.

- E3M, fondé en 1975 à Berne et en 1979 à Lausanne, s'adresse aux autorités scolaires et aux enseignants qui désirent être conseillés et formés dans le domaine du développement.

- La communauté de travail est représentée à la Commission consultative pour la coopération au développement. Le poste de coordinateur, créé en 1981, permettra d'être encore plus actif dans la formation de l'opinion en matière de politique du développement.

\section{AUTEUR \\ RICHARD GERSTER}

Koordinator für Entwicklungspolitik I3W 